\title{
Nucleus Accumbens Medium Spiny Neurons Target Non-Dopaminergic Neurons in the Ventral Tegmental Area
}

\author{
Yanfang Xia, Joseph R. Driscoll, Linda Wilbrecht, Elyssa B. Margolis, Howard L. Fields, and Gregory O. Hjelmstad \\ Ernest Gallo Clinic and Research Center, Wheeler Center for the Neurobiology of Addiction, and Department of Neurology, University of California, San \\ Francisco, Emeryville, California 94608
}

The midbrain ventral tegmental area (VTA) projection to the nucleus accumbens (NAc) is implicated in motivation and reinforcement. A significant number of NAc medium spiny neurons (MSNs) project back to the VTA, although the nature of this projection is essentially unknown. For example, do NAc MSNs directly target accumbens-projecting dopamine neurons and do they act via the $\mathrm{GABA}_{\mathrm{A}}$ or $\mathrm{GABA}_{\mathrm{B}}$ receptor? To address these issues, we expressed the light-sensitive channel rhodopsin-2 in the rat NAc and made electrophysiological recordings from VTA neurons ex vivo. We found that the NAc directly targets non-dopaminergic VTA neurons, including some that project back to the NAc. These MSN GABAergic terminals are opioid sensitive and act via $\mathrm{GABA}_{\mathrm{A}}$ receptors.

\section{Introduction}

The ventral tegmental area (VTA) projection to the nucleus accumbens (NAc) is a critical element of circuits that mediate appetitive behaviors (Carr and Sesack, 2000a; Fields et al., 2007; Humphries and Prescott, 2010). Although considerable focus has been placed on the role of the dopamine projection from the VTA to the NAc, a significant number of VTA GABA neurons also project to the NAc (Van Bockstaele and Pickel, 1995; Carr and Sesack, 2000b; Margolis et al., 2006b). Moreover, a subset of NAc medium spiny neurons (MSNs) sends a reciprocal GABAergic projection back to the VTA (Nauta et al., 1978; Heimer et al., 1991; Kalivas et al., 1993; Lu et al., 1998; Usuda et al., 1998; Tripathi et al., 2010). This projection is thought to mediate a "long-loop" inhibitory feedback to regulate dopamine neuron activity (Einhorn et al., 1988; Rahman and McBride, 2000). However, it is unresolved whether the axon terminals of the MSNs synapse onto NAc-projecting dopamine neurons or a different class of VTA neuron.

The nature of the synaptic connection is also unknown. It has been proposed that the NAc projection to the VTA produces an IPSC mediated exclusively by $\mathrm{GABA}_{\mathrm{B}}$ receptors (Sugita et al., 1992; Cameron and Williams, 1993). However, this model was based on indirect evidence and, because of technical limitations, has never been directly tested.

The recent development of optogenetic tools provides a novel method for isolating the action of specific afferent projections to

Received March 24, 2011; revised April 1, 2011; accepted April 6, 2011.

Author contributions: Y.X., L.W., E.B.M., H.L.F., and G.O.H. designed research; Y.X., J.R.D., and G.O.H. performed research; Y.X., J.R.D., and G.O.H. analyzed data; Y.X., L.W., E.B.M., H.L.F., and G.O.H. wrote the paper.

The authors declare no competing financial interests.

This work was supported by the State of California for medical research on alcohol and substance abuse through the University of California, San Francisco and by the Wheeler Center for the Neurobiology of Addiction. We thank Kaidi He for technical assistance.

Correspondence should be addressed to Gregory Hjelmstad, Ernest Gallo 0 Clinic and Research Center, 5858 Horton Street, Suite \#200, Emeryville, CA 94608. E-mail: gregh@gallo.ucsf.edu.

DOI:10.1523/JNEUROSCI.1504-11.2011

Copyright $\odot 2011$ the authors $\quad 0270-6474 / 11 / 317811-06 \$ 15.00 / 0$ neurons in a region with heterogeneous anatomical connectivity. In this study, we used a viral vector to express channel rhodopsin-2 (ChR2) in neurons of the NAc of rats and optically stimulated their axon terminals during ex vivo whole-cell recordings from VTA neurons in a midbrain slice. We found that NAc MSNs target non-dopaminergic VTA neurons, including non-dopaminergic neurons that project back to the NAc. Moreover, this connection is mediated by $\mathrm{GABA}_{\mathrm{A}}$ receptors and is inhibited by $\mu$-opioids, providing a potential mechanism for opioid reward.

\section{Materials and Methods}

Animals. Surgeries were performed on 27- to 29-d-old (70-80 g) male Sprague Dawley rats. Animals were anesthetized with isoflurane. Adeno-associated virus containing ChR2-tdtomato (AAV2/1 CAG::ChR2.tdtomato, a kind gift from Karel Svoboda) was bilaterally injected ( $1 \mu \mathrm{l}$ in each side) using a Hamilton syringe stereotaxically placed into the NAc shell (anteroposterior, $+1.5 \mathrm{~mm}$ from bregma; mediolateral, $\pm 0.8 \mathrm{~mm}$ from bregma; ventral, $-6.7 \mathrm{~mm}$ from skull surface). The injector was left in place for $5 \mathrm{~min}$, raised $1 \mathrm{~mm}$, and left for an additional 5 min before being completely removed. Animals were then returned to their home cages for $14-17 \mathrm{~d}$ before electrophysiological experiments were performed. For retrograde tracer experiments, neuro-DiI ( $0.3 \mu \mathrm{l}, 7 \%$ in ethanol; Biotium) was slowly injected (over 5 $\mathrm{min}$ ) into the NAc $2-3 \mathrm{~h}$ after the injection of the virus. Only data from rats in which the infection was confirmed were accepted.

Slice preparation and electrophysiology. Coronal NAc slices $(350 \mu \mathrm{m}$ thick) or horizontal midbrain slices (150-200 $\mu \mathrm{m}$ thick) including the VTA were prepared using a vibratome (Leica Instruments) in artificial CSF (ACSF) containing the following (in $\mathrm{mm}$ ): $119 \mathrm{NaCl}, 2.5 \mathrm{KCl}, 1.3$ $\mathrm{MgSO}_{4}, 1.0 \mathrm{NaH}_{2} \mathrm{PO}_{4}, 2.5 \mathrm{CaCl}_{2}, 26.2 \mathrm{NaHCO}_{3}$, and 11 glucose (saturated with $95 \% \mathrm{O}_{2} / 5 \% \mathrm{CO}_{2}$ ). Slices were submerged in ACSF and allowed to recover for $>1 \mathrm{~h}$ at room temperature.

Individual slices were visualized under an upright microscope with differential interference contrast optics and infrared and epifluorescent illumination. Whole-cell recordings were made with $2.5-4 \mathrm{M} \Omega$ pipettes containing the following (in $\mathrm{mM}$ ): $123 \mathrm{~K}$-gluconate, 10 HEPES, 0.2 EGTA, $8 \mathrm{NaCl}, 2 \mathrm{MgATP}$, and $0.3 \mathrm{Na}_{3} \mathrm{GTP}$, pH 7.2 (osmolarity adjusted to $275 \mathrm{mOsm}$ ). In some experiments, $0.1 \%$ biocytin was included in the recording solution. Recordings were made using a Multiclamp 700A or Axopatch 1-D amplifier (Molecular Devices), filtered at $2 \mathrm{kHz}$, and collected at $5 \mathrm{kHz}$ using procedures written for Igor Pro (Wavemetrics). 
ChR2 was stimulated by flashing $470 \mathrm{~nm}$ light (1-5 ms) through the light path of the microscope using a high-powered LED (XR-E XLamp LED; Cree) powered by an LED driver (Mightex Systems) under computer control. Electrically evoked $\mathrm{GABA}_{\mathrm{B}}$ IPSCs were isolated with picrotoxin $(100 \mu \mathrm{M})$, DNQX $(10 \mu \mathrm{M})$, sulpiride $(10 \mu \mathrm{M})$, strychnine $(1 \mu \mathrm{M})$, and D-AP-5 $(10 \mu \mathrm{M})$ and were evoked with a train of seven pulses given once every $30 \mathrm{~s}$ through a bipolar stimulating electrode placed $\sim 50 \mu \mathrm{m}$ from the recorded neuron. Light-evoked IPSC amplitudes were calculated by comparing a 2 $\mathrm{ms}$ period at the peak of the response with a similar period just before light stimulation. The significance of drug effects was determined comparing the last $4 \mathrm{~min}$ of baseline with the last 4 min of drug application. Baclofen currents were determined by measuring a $1 \mathrm{~min}$ average during the peak response compared with the baseline period. HCN currents $\left(I_{\mathrm{h}}\right)$ were recorded by voltage clamping cells at -60 $\mathrm{mV}$ and applying a series of steps from -40 to $-120 \mathrm{mV}$. The $I_{\mathrm{h}}$ magnitude was measured as the difference between the initial capacitative response to the voltage step and the final current. Series resistance was monitored online by measuring the peak of the capacitance transient in response to a $-4 \mathrm{mV}$ voltage step applied at the onset of each sweep. All drugs were applied by bath perfusion. Stock solutions of drugs are made and diluted (typically 1:1000) into ACSF immediately before application.

Statistical analyses were performed using the $\chi^{2}$ test, Student's $t$ test, or appropriate ANOVA as described in the text. Data are presented as mean \pm SEM. Significance is defined as $p<0.05$.

Immunocytochemistry. For tyrosine hydroxylase (TH) immunoreactivity, immediately after recording, slices were fixed in $4 \%$ formaldehyde for $2 \mathrm{~h}$, then washed thoroughly, and stored at $4^{\circ} \mathrm{C}$ in PBS. Sections were preblocked for $2 \mathrm{~h}$ in PBS plus $0.3 \%$ (v/v) Tween 20, 0.2\% BSA, and 5\% normal goat serum and then incubated for $48 \mathrm{~h}$ at $4^{\circ} \mathrm{C}$ with a rabbit anti-tyrosine hydroxylase polyclonal antibody (1:100). The slices were washed thoroughly in PBS with $0.3 \%$ Tween 20 before being agitated overnight at $4^{\circ} \mathrm{C}$ with Cy5 anti-rabbit secondary antibody (1:100) and dichlorotriazinylaminofluorescein-conjugated streptavidin $(3.25 \mu \mathrm{l} /$ $\mathrm{ml}$ ). Sections were mounted on slides using Bio-Rad Fluoroguard Antifade Reagent mounting media and visualized under a Carl Zeiss LSM 510 META microscope. Neurons were only considered TH $(-)$ if they were in the same focal plane as other $\mathrm{TH}(+)$ neurons.

Injection sites were fixed in $4 \%$ formaldehyde, and coronal sections $(50 \mu \mathrm{m})$ containing the injection site were prepared using a sliding microtome. Slices were preblocked in $10 \%$ normal goat serum for $30 \mathrm{~min}$ and then incubated with a rabbit anti-RFP antibody (1:2000) for $48 \mathrm{~h}$. Slices were washed thoroughly before being incubated with FITCconjugated affinpure goat anti-rabbit secondary antibody (1:200). Sections were mounted and visualized as above. Only data from rats in which the infection was confined to the NAc were accepted (although there was often some infection along the injection tract, control injections into the dorsal striatum did not result in ChR2 expression in the VTA).

\section{Results}

Microinjection of AAV2/1 CAG::ChR2.tdtomato into the NAc resulted in expression of ChR2 in MSNs (Fig. 1A). In whole-cell current-clamp recordings from infected MSNs in NAc slices prepared 14-17 d after microinjection, brief (1-5 ms) light pulses evoked depolarizations that varied with the intensity of the light,
B

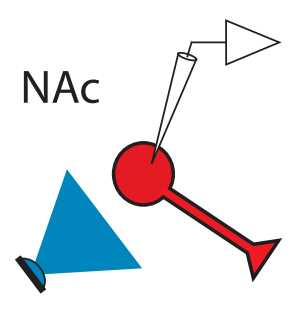

C

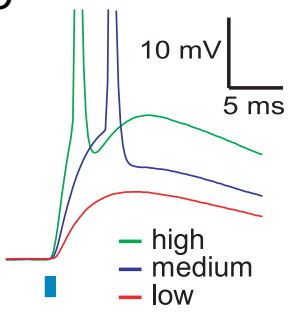

$\mathrm{E}$

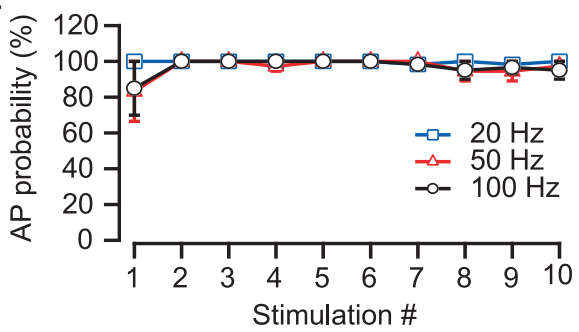

F

G
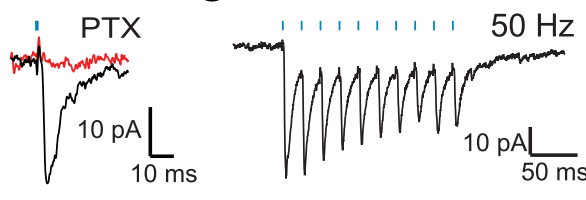

Figure 1. ChR2-expression in the NAc. A, Confocal image of ChR2-tdtomato expression (red) in NAc neurons. Scale bar, $50 \mathrm{im}$. showing responses to $1 \mathrm{~ms}$ pulses of light at three different intensities. $\boldsymbol{D}$, MSNs can follow trains of light pulses up to $100 \mathrm{~Hz}$. $\boldsymbol{E}$, 列

in which higher intensities produced action potentials (Fig. 1C). Trains of $1 \mathrm{~ms}$ light pulses reliably produced action potentials at frequencies up to $100 \mathrm{~Hz}$ (Fig. $1 D, E$ ). Trains with longerduration ( $5 \mathrm{~ms}$ ) light pulses produced more erratic responses: double spikes early in the trains and less reliable spiking later in the trains $(n=5)$ (data not shown). In voltage-clamp recordings from uninfected, neighboring MSNs, light evoked an inward current when the neuron was held at $-75 \mathrm{mV}$ that was blocked by the $\mathrm{GABA}_{\mathrm{A}}$ receptor antagonist picrotoxin $(100 \mu \mathrm{M})($ Fig. $1 F)$. These IPSCs followed trains of light (Fig. 1G) and exhibited short-term depression similar to that seen using electrical stimulation (Hjelmstad, 2004). Thus, ChR2-expressing MSNs of the ventral striatum are able to reliably follow high-frequency trains of light leading to local release of GABA.

In horizontal midbrain slices containing the VTA, we found strong fluorescence in fibers but not in cell bodies (Fig. 2A), consistent with transport of ChR2 to the axon terminal fields of NAc MSNs. We made whole-cell voltage-clamp $\left(V_{\mathrm{m}}\right.$ of $\left.-45 \mathrm{mV}\right)$ recordings from VTA neurons and optically stimulated MSN fibers (Fig. $2 B$ ). In $\sim 40 \%$ of recordings, brief ( $1-5 \mathrm{~ms}$ ) light stimulation of the slice resulted in a fast IPSC with a mean amplitude of $68.9 \pm 11.1 \mathrm{pA}(n=62)$. This light-evoked IPSC was also sensitive to picrotoxin ( $95 \pm 3 \%, n=24)$, indicating that it is mediated by $\mathrm{GABA}_{\mathrm{A}}$ receptors (Fig. $2 \mathrm{C}$ ). Consistent with a previous report of recordings of light-evoked EPSCs from cortical neurons (Cruikshank et al., 2010), this transmitter release is clearly dependent on action potentials, because it was completely abolished by the sodium channel blocker TTX $(1 \mu \mathrm{M} ; n=3$ ) (data not shown). Finally, after blocking the $\mathrm{GABA}_{\mathrm{A}}$ receptor response with picrotoxin, increasing the number and frequency of stimulation (up to 10 pulses at $20-100 \mathrm{~Hz}$ ) did not elicit a slow $\mathrm{GABA}_{\mathrm{B}}$ 
A

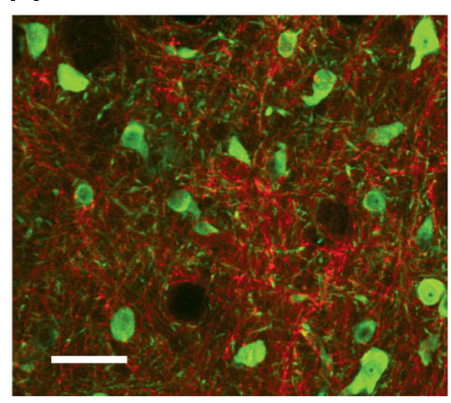

B

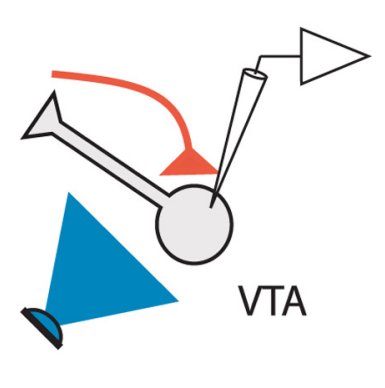

C
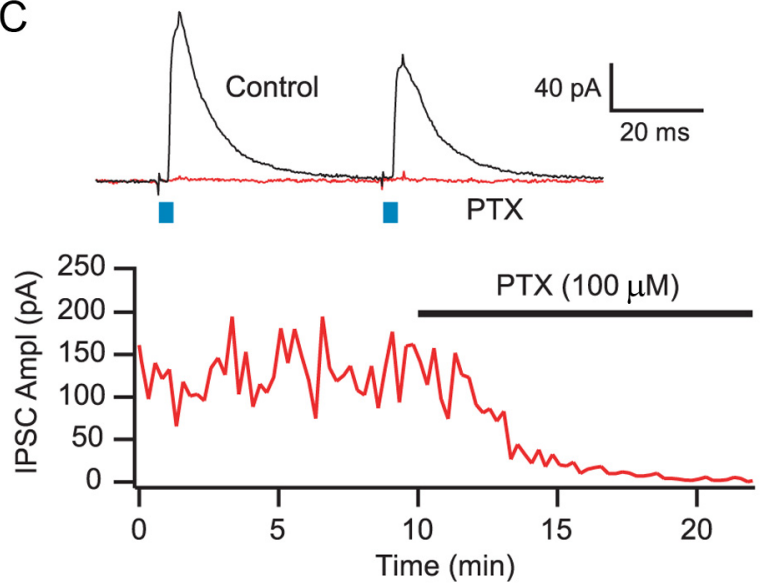

Figure 2. ChR2-expressing MSNs project to the VTA. A, Confocal image of ChR2-tdtomato expression (red) in axon terminals within the VTA near $\mathrm{TH}^{+}$neurons (green) after microinjection into the NAc. Scale bar, 50 im. $\boldsymbol{B}$, Diagram of experimental design: light stimulates ChR2expressing NAC MSN terminals (red) while recording from uninfected VTA neurons. $C$, Example recording from VTA neuron showing responses to two 3 ms pulses of light, $50 \mathrm{~ms}$ apart. This IPSC was entirely blocked after application of picrotoxin (PTX). Bottom graph shows time course of pharmacological effect.

receptor-mediated IPSC $(n=24)$ (Fig. $3 A)$, although electrical stimulation clearly evokes a frequency-dependent slow $\mathrm{GABA}_{\mathrm{B}}$ IPSC in VTA neurons $(n=5)$ (Fig. $3 B$ ).

Although these data imply that the NAc input is exclusively mediated by $\mathrm{GABA}_{\mathrm{A}}$ receptors, one possible explanation for the lack of an observed $\mathrm{GABA}_{\mathrm{B}}$ receptor-mediated component to the IPSC is that, similar to the hippocampus (Scanziani, 2000), the $\mathrm{GABA}_{\mathrm{B}}$ receptors are predominantly extrasynaptic, and uptake through GABA transporters effectively lowers the concentration of synaptically released GABA at the more distant $\mathrm{GABA}_{\mathrm{B}}$ receptor. To test this, we bath applied the GAT1 inhibitor NNC-711 [1-(2-(((diphenylmethylene)amino)oxy)ethyl)-1,2,5,6-

tetrahydro-3-pyridinecarboxylic acid hydrochloride] $(10 \mu \mathrm{M})$ in the presence of picrotoxin. NNC-711 had no effect on optically evoked MSN inputs (control, $0.7 \pm 0.4 \mathrm{pA}$; drug, $0.3 \pm 0.8 \mathrm{pA}$; $n=11$ ) (Fig. $3 C$ ), although it clearly enhances electrically evoked GABA $_{\mathrm{B}}$ IPSCs $(48 \pm 12 \%, n=6, p<0.05)$ (Fig. 3D).

In the mouse VTA, dopamine and GABA neurons exhibit different sensitivities to $\mathrm{GABA}_{\mathrm{B}}$ agonists (Cruz et al., 2004). Thus,

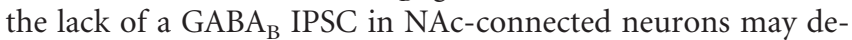
pend on the class of neurons targeted by NAc MSNs. To test this, we bath applied a high dose $(20 \mu \mathrm{M})$ of the $\mathrm{GABA}_{\mathrm{B}}$ receptor agonist baclofen in NAc-connected neurons. Baclofen produced a small, nonsignificant outward current in these neurons $(n=5)$ (Fig. 3E) comparable with the baclofen response in a set of immunocytochemically identified $\mathrm{TH}(-)$ neurons from control slices and significantly smaller than the response seen in control
A

$\mathrm{B}$

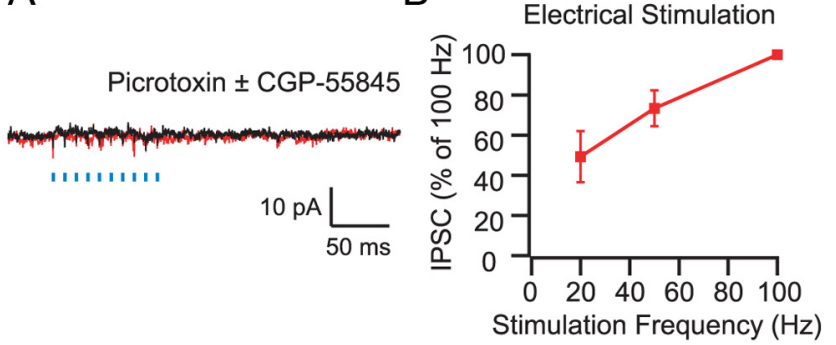

C

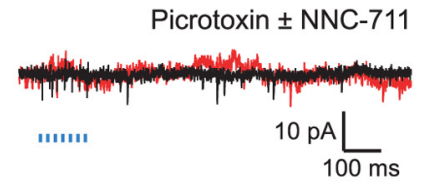

D

Electrical Stimulation

E

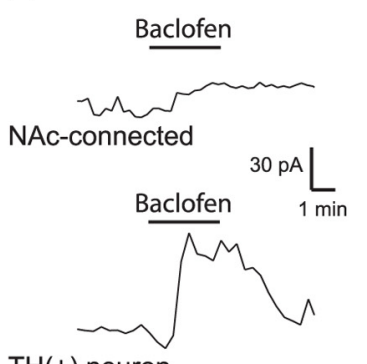

$\mathrm{TH}(+)$ neuron

F
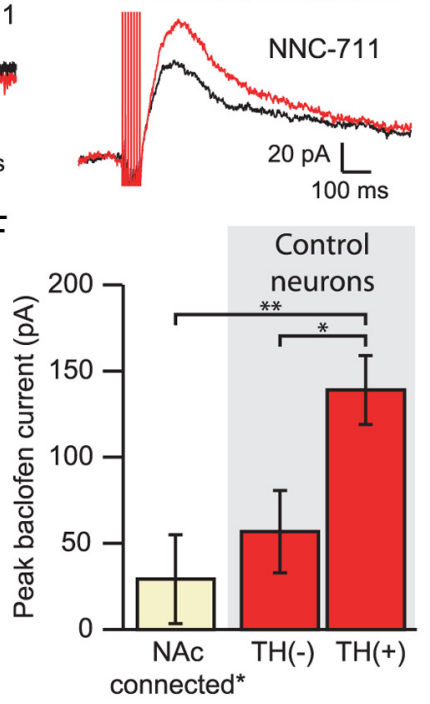

Figure 3. Lack of light-evoked $G A B A_{B}$ response in VTA neurons. $A$, Average of five consecutive traces in an NAc-connected neuron after the $G_{A B A}$ response was blocked with $100 \mu \mathrm{m}$ picrotoxin and after application of the GABA ${ }_{B}$ receptor antagonist CGP-55845 [(2S)-3-[(15)-1(3,4-dichlorophenyl)ethyl]amino-2-hydroxypropyl)(phenylmethyl)phosphinic acid] shows no response to $100 \mathrm{~Hz}$ light stimulation. $\boldsymbol{B}$, The amplitude of electrically evoked $\mathrm{GABA}_{B}$ IPSCS depends on the stimulation frequency. $C$, The addition of NNC-711 (10 $\mu \mathrm{M})$ does not reveal a

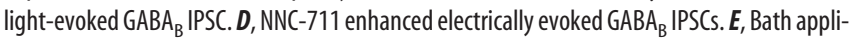
cation of $20 \mu \mathrm{m}$ baclofen produced a small outward current in a neuron that received input from the NAc (top) compared with the response of a control TH (+) neuron (bottom). $\boldsymbol{F}$, Connected neurons $(n=5)$ showed significantly smaller baclofen responses than $\mathrm{TH}(+)$ control neurons $(n=9)$, which had larger responses to baclofen than identified TH $(-)$ neurons $(n=5) .{ }^{*} p<$ $0.05,{ }^{* *} p<0.01$.

TH $(+)$ neurons $(p<0.01$, one-way ANOVA with Holm-Sidak test) (Fig. 3F).

Although all dopamine neurons in the rat VTA express a hyperpolarization activated cation current $\left(I_{\mathrm{h}}\right)$, nearly half of $I_{\mathrm{h}}(+)$ neurons are non-dopaminergic (Margolis et al., 2006a). We found that the NAc disproportionately targets $I_{\mathrm{h}}(-)$ (i.e., non-dopaminergic) VTA neurons: 20 of 62 (32.3\%) of connected neurons were $I_{\mathrm{h}}(-)$ compared with $14.9 \%$ of unconnected neurons recorded from the same group of animals $\left(p<0.02, \chi^{2}\right.$ test) (Fig. $\left.4 A\right)$. Among $I_{\mathrm{h}}(+)$ neurons, the size of the $I_{\mathrm{h}}$ did not correlate with whether the neuron showed a response to light stimulation (Fig. $4 B$ ).

Because $I_{\mathrm{h}}(+)$ neurons can either be $\mathrm{TH}(+)$ or $\mathrm{TH}(-)$, in some experiments, we included biocytin in our whole-cell recording solution and, after the recording, processed the tissue for $\mathrm{TH}$ immunoreactivity. None of the 19 connected neurons that were successfully recovered stained positive for $\mathrm{TH}\left(14 \mathrm{I}_{\mathrm{h}}(+)\right.$ and $5 I_{\mathrm{h}}(-)$ neurons) (Fig. 4C). In contrast, we also recovered a subset of the unconnected neurons that were recorded for an equivalent length of time and, of these, 6 of 14 (43\%) were confirmed to be TH $(+)\left(p<0.01, \chi^{2}\right.$ test $)$. 
Although these data indicate that NAc MSNs target VTA non-dopamine neurons, separate groups of VTA neurons project to different targets and randomly sampling from the VTA may underrepresent specific neuronal populations. Therefore, to determine whether NAc-projecting neurons, especially NAc-projecting dopamine neurons, are innervated by NAc afferents, shortly after injecting the virus, we also microinjected the retrograde tracer DiI into the NAc. DiI injection into the NAc labeled cell bodies in the VTA that overlapped with fibers containing ChR2 (Fig. 5A). The projection to the NAc from the VTA contains both dopamine and non-dopamine neurons (Swanson, 1982). Importantly, within this specific projection, the dopamine neurons exhibit longer action potential durations than the non-dopamine (presumably GABAergic) neurons (Maeda and Mogenson, 1980; Yim and Mogenson, 1980a; Margolis et al., 2008b). Thus, we measured the action potential durations to predict the neurotransmitter content of the recorded neuron. Importantly, this method also allowed us to record from several retrogradely labeled neurons within the same slice.

From seven animals, we recorded 24 retrogradely labeled VTA neurons (Fig. $5 B)$. Of these, six neurons responded to light stimulation with an IPSC (Fig. 5C). In each of these neurons, we also recorded action potentials in current-clamp mode. All of the connected neurons had action potential durations briefer than the median of the entire population. Moreover, the mean action potential duration for connected NAc-projecting neurons was significantly shorter than the action potential duration from unconnected NAcprojecting neurons $(p<0.05)$ (Fig. 5D). These data indicate that NAc MSNs target non-dopaminergic NAc-projecting VTA neurons.

Opioids have powerful motivational and reinforcing actions within the VTA (Bals-Kubik et al., 1993; Devine and Wise, 1994). These actions are thought to be attributable to the release of dopamine neurons from $\mathrm{GABA}_{\mathrm{A}}$ inhibition via a set of intrinsic GABAergic interneurons (Johnson and North, 1992; Koob and Volkow, 2010). Consistent with this idea, electrically stimulated $\mathrm{GABA}_{\mathrm{A}}$ receptor-mediated IPSCs in the VTA are inhibited by the bath application of $\mu$-opioid agonists (Bonci and Williams, 1997; Nugent et al., 2007; Margolis et al., 2008a). However, given that GABAergic afferents to VTA neurons arise from a variety of extrinsic sources, it is unclear which neurons give rise to the GABAergic terminals that are modulated by ì agonists in the
A
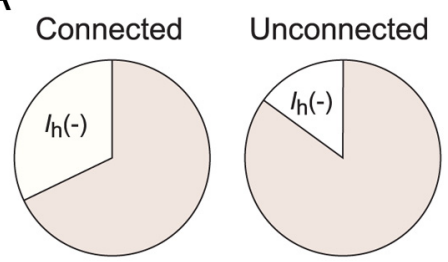

C

\begin{tabular}{r|c|c|} 
& \multicolumn{1}{c}{$\mathrm{TH}(+)$} & $\mathrm{TH}(-)$ \\
\cline { 2 - 3 } Connected & 0 & 19 \\
\cline { 2 - 3 } Unconnected & 6 & 8 \\
\cline { 2 - 3 }
\end{tabular}

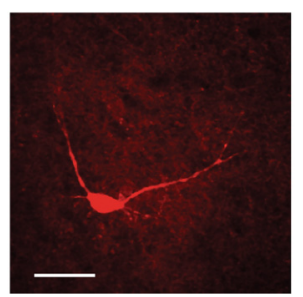

B
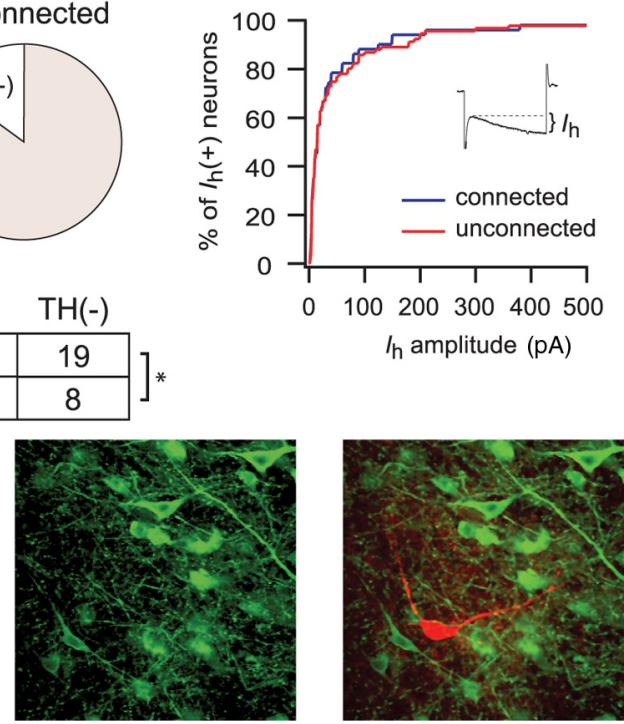

Figure 4. NAC MSNs target VTA non-dopamine neurons. $\boldsymbol{A}$, Proportion of connected and unconnected neurons that express the $I_{\mathrm{h}}$. $\boldsymbol{B}$, Among $I_{\mathrm{h}}$-expressing neurons, there was no difference in the magnitude of the $I_{\mathrm{h}}$ in connected and unconnected neurons. $\boldsymbol{C}$, Example of a biocytin-filled TH (-) neuron that responded to light stimulation with an IPSC. Biocytin, Red; TH, green. Inset shows summary of TH immunocytochemistry for connected and unconnected neurons. ${ }^{*} p<0.01$.

\section{A}
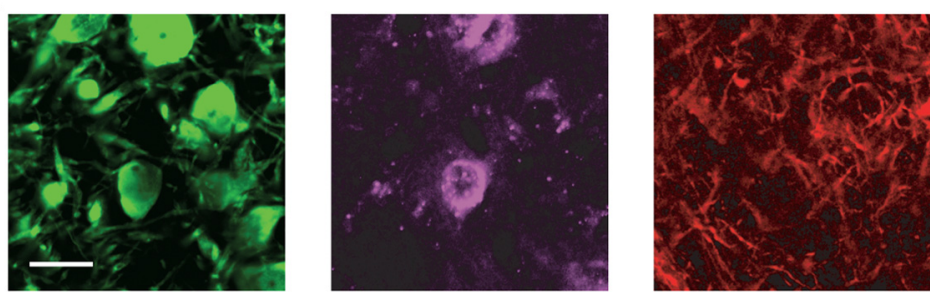

B

C
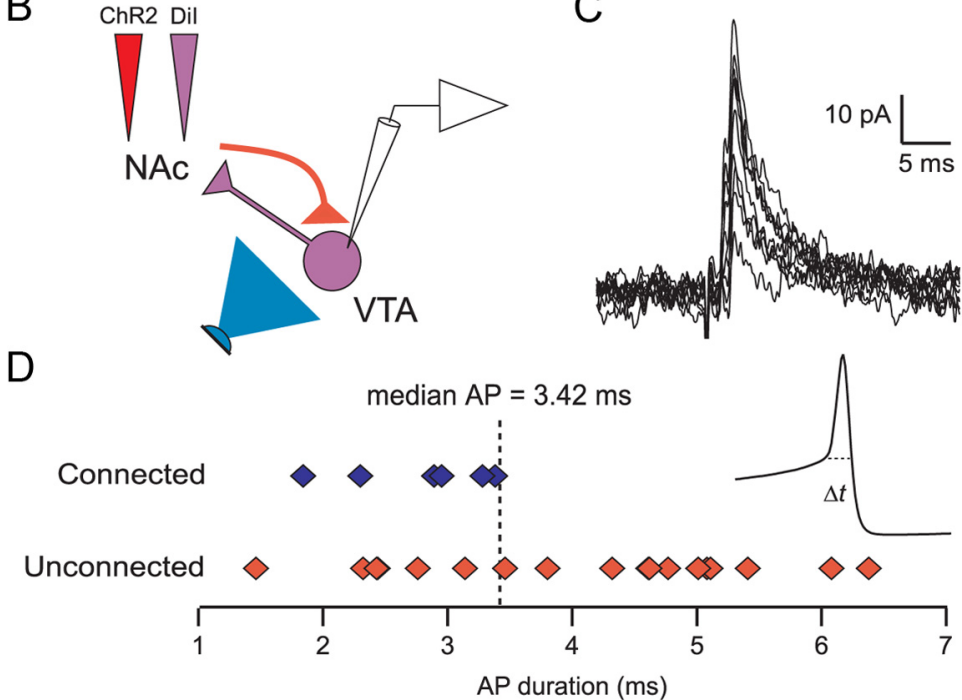

Figure 5. NAc MSNs target NAc-projecting VTA neurons. $\boldsymbol{A}$, Triple-labeled VTA slice showing TH (green), Dil (violet), and ChR2 (red) after microinjection of Dil and ChR2 into the NAc. Scale bar, $20 \mathrm{im}$. B, Diagram of experimental design. Light stimulation (blue) of ChR2-expressing NAc MSN terminals (red) while recording from retrogradely labeled VTA neurons (violet). $\boldsymbol{C}$, Ten consecutive light-evoked IPSCs from a retrogradely labeled VTA neuron. D, Distribution of action potential durations from connected (blue) and unconnected (red) NAc-projecting neurons. Inset shows average of 10 consecutive action potentials (AP; from example in $\boldsymbol{C}$ ). Dashed line indicates where action potential duration was measured. 


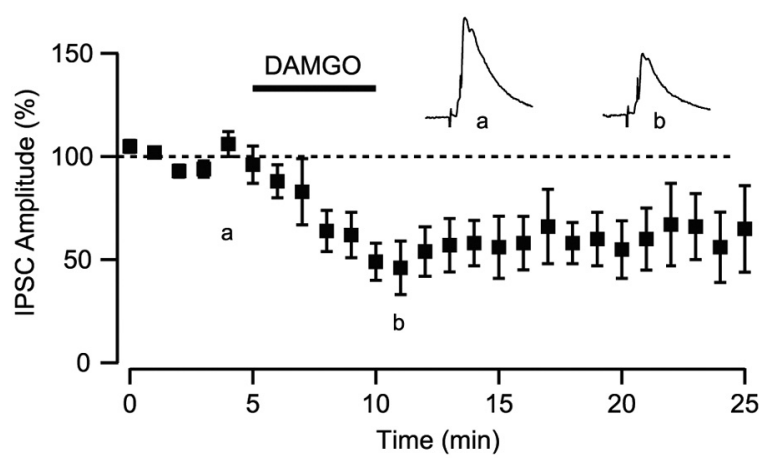

Figure 6. NAc projections to the VTA are inhibited by $\mu$-opioids. Bath application of the $\mu$-opioid receptor agonist DAMGO $(1 \mu \mathrm{m})$ inhibited light-evoked IPSCs arising from the NAC $(n=9)$. Top traces show average of five consecutive IPSCs from control (left) and in DAMGO (right).

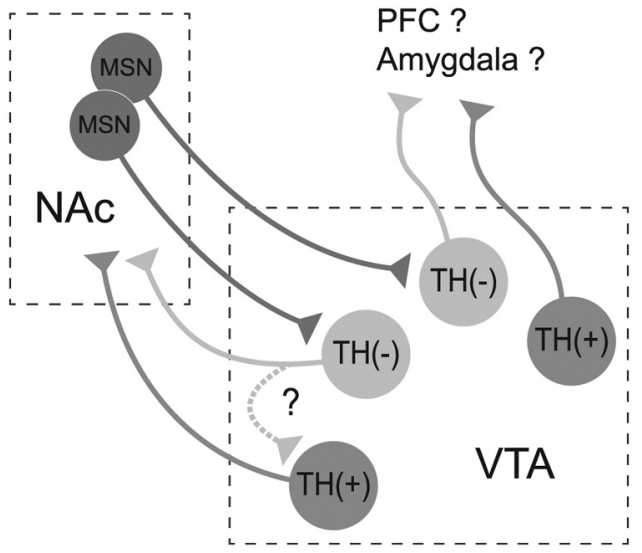

Figure 7. Circuit diagram of NAc connections within the VTA MSNs of the NAc synapse onto non-dopaminergic neurons in the VTA, including some that project back to the NAc. NAc MSNs do not synapse onto VTA dopamine neurons but may indirectly modulate their activity through local connections within the VTA.

VTA. We measured light-evoked IPSCs in the VTA and bath applied the $\mu$-opioid agonist DAMGO $(1 \mu \mathrm{M})$. Bath application of DAMGO inhibited the amplitude of the IPSC by $29.1 \pm 9.4 \%$ $(p<0.05, n=8)$ (Fig. 6).

\section{Discussion}

Using virally directed ChR2 to selectively stimulate a distinct subset of afferent inputs (Zhang et al., 2007), we have demonstrated that the synaptic connections arising from the NAc onto VTA neurons constitute an opioid-sensitive, fast inhibitory connection mediated by $\mathrm{GABA}_{\mathrm{A}}$ receptors. These afferents preferentially target non-dopaminergic VTA neurons, including a population that projects back to the NAc (Fig. 7).

The VTA is a highly heterogeneous brain region, composed of dopamine, GABA, and glutamate neurons (Swanson, 1982; Margolis et al., 2006a; Yamaguchi et al., 2007; Nair-Roberts et al., 2008). A significant proportion of NAc-projecting VTA neurons are GABAergic and stain positive for GAD67 (Carr and Sesack, 2000b; Margolis et al., 2006b). Intriguingly, Carr and Sesack (2000b) observed that glutamatergic afferents arising from the prefrontal cortex preferentially target these GABAergic NAc projection neurons and not NAc-projecting dopamine neurons. Our data indicate that MSNs similarly target non-dopaminergic NAcprojecting neurons. Thus, activation of the long-loop feedback from the NAc will not directly inhibit VTA dopamine neurons.
However, this feedback could indirectly inhibit VTA dopamine neurons if the NAc MSNs target VTA glutamate neurons, which do make local collaterals onto dopamine neurons (Dobi et al., 2010). Alternatively, if the NAc-connected non-dopaminergic neurons include GABAergic neurons that make local contacts with dopamine neurons (Omelchenko and Sesack, 2009), activation of this projection could increase dopamine neuron firing. Such a GABA-GABA-DA loop has been demonstrated in the substantia nigra (Grace and Bunney, 1985) and is supported by a recent optogenetic study showing that MSNs in the dorsal striatum synapse onto GABAergic neurons in the substantia nigra pars reticulata but not dopamine neurons in the pars compacta (Chuhma et al., 2011). If a parallel GABA-GABA-DA loop exists from the ventral striatum, inhibition of MSNs (such as that seen with cocaine) will provide a negative feedback to dopamine neurons (Einhorn et al., 1988).

Previous authors have speculated that the NAc input to the VTA is mediated exclusively through the $\mathrm{GABA}_{\mathrm{B}}$ receptor (Sugita et al., 1992; Cameron and Williams, 1993). This model was based on the differential sensitivity of VTA $G_{A B A}$ and $G_{A B A}$ receptor-mediated IPSCs to 5-HT (Johnson et al., 1992; Sugita et al., 1992) and to $\mathrm{D}_{1}$ dopamine receptor agonists (Cameron and Williams, 1993). Given the low expression levels of 5-HT and $\mathrm{D}_{1}$ dopamine receptors within the VTA in conjunction with higher expression levels within the NAc, it was proposed that these receptors were expressed on presynaptic terminals arising from extrinsic sources, namely, those arising from the NAc. Because only the GABA $\mathrm{BPSC}_{\mathrm{B}}$ shows sensitivity to $5-\mathrm{HT}$ and $\mathrm{D}_{1}$ agonists, it was concluded that the NAc input targets $\mathrm{GABA}_{\mathrm{B}}$ receptor-only synapses. Our data demonstrate the opposite; inputs from the NAc signal through $\mathrm{GABA}_{\mathrm{A}}$ receptors, a result that is consistent with in vivo experiments showing that inhibition produced by stimulation of the NAc can be attenuated by local iontophoresis of a $\mathrm{GABA}_{\mathrm{A}}$ receptor antagonist (Yim and Mogenson, 1980b).

That we could not evoke a $\mathrm{GABA}_{\mathrm{B}}$ receptor-mediated IPSC raises the possibility that $\mathrm{GABA}_{\mathrm{B}}$ receptors are segregated to a different set of synapses or perhaps a separate class of neurons within the VTA. Our data showing that connected neurons show little response to bath application of the $\mathrm{GABA}_{\mathrm{B}}$ receptor agonist baclofen argues that NAc-connected (non-dopamine) neurons have few functional $\mathrm{GABA}_{\mathrm{B}}$ receptors, extending previous results from the mouse VTA (Cruz et al., 2004) and providing a circuitbased framework for in vivo studies investigating the regulation of dopamine by $\mathrm{GABA}_{\mathrm{B}}$ receptors (Klitenick et al., 1992; Xi and Stein, 1998; Laviolette et al., 2004).

That the input arising from NAc signals through $\mathrm{GABA}_{\mathrm{A}}$ receptors raises the possibility that synaptic mechanisms that have previously been attributed to local interneurons may be additionally or entirely mediated by afferents from extrinsic sources. Most notable is the inhibition of GABA release by opioids (Johnson and North, 1992). This opioid-induced decrease in GABA release leads to the disinhibition of dopamine neurons that can produce opioid reward. However, VTA opioids can also signal reward in a dopamine-independent manner (Bechara et al., 1992; Nader and van der Kooy, 1997). We show that GABAergic inputs from the NAc onto non-dopaminergic neurons are also sensitive to $\mu$-opioids. Although a subset of these neurons project to the NAc, opioid reward as measured by conditioned place preference can persist after lesion of the NAc (Olmstead and Franklin, 1996, 1997; White et al., 2005), implicating projections to other brain regions such as the prefrontal cortex, hippocampus, and amygdala (Swanson, 1982). The current results represent a first step toward resolving the neural mechanism of opioid reward. 


\section{References}

Bals-Kubik R, Ableitner A, Herz A, Shippenberg TS (1993) Neuroanatomical sites mediating the motivational effects of opioids as mapped by the conditioned place preference paradigm in rats. J Pharmacol Exp Ther 264:489-495.

Bechara A, Harrington F, Nader K, van der Kooy D (1992) Neurobiology of motivation: double dissociation of two motivational mechanisms mediating opiate reward in drug-naive versus drug-dependent animals. Behav Neurosci 106:798-807.

Bonci A, Williams JT (1997) Increased probability of GABA release during withdrawal from morphine. J Neurosci 17:796-803.

Cameron DL, Williams JT (1993) Dopamine D1 receptors facilitate transmitter release. Nature 366:344-347.

Carr DB, Sesack SR (2000a) GABA-containing neurons in the rat ventral tegmental area project to the prefrontal cortex. Synapse 38:114-123.

Carr DB, Sesack SR (2000b) Projections from the rat prefrontal cortex to the ventral tegmental area: target specificity in the synaptic associations with mesoaccumbens and mesocortical neurons. J Neurosci 20:3864-3873.

Chuhma N, Tanaka KF, Hen R, Rayport S (2011) Functional connectome of the striatal medium spiny neuron. J Neurosci 31:1183-1192.

Cruikshank SJ, Urabe H, Nurmikko AV, Connors BW (2010) Pathwayspecific feedforward circuits between thalamus and neocortex revealed by selective optical stimulation of axons. Neuron 65:230-245.

Cruz HG, Ivanova T, Lunn ML, Stoffel M, Slesinger PA, Lüscher C (2004) Bi-directional effects of GABA(B) receptor agonists on the mesolimbic dopamine system. Nat Neurosci 7:153-159.

Devine DP, Wise RA (1994) Self-administration of morphine, DAMGO, and DPDPE into the ventral tegmental area of rats. J Neurosci 14: $1978-1984$.

Dobi A, Margolis EB, Wang HL, Harvey BK, Morales M (2010) Glutamatergic and nonglutamatergic neurons of the ventral tegmental area establish local synaptic contacts with dopaminergic and nondopaminergic neurons. J Neurosci 30:218-229.

Einhorn LC, Johansen PA, White FJ (1988) Electrophysiological effects of cocaine in the mesoaccumbens dopamine system: studies in the ventral tegmental area. J Neurosci 8:100-112.

Fields HL, Hjelmstad GO, Margolis EB, Nicola SM (2007) Ventral tegmental area neurons in learned appetitive behavior and positive reinforcement. Annu Rev Neurosci 30:289-316.

Grace AA, Bunney BS (1985) Opposing effects of striatonigral feedback pathways on midbrain dopamine cell activity. Brain Res 333:271-284.

Heimer L, Zahm DS, Churchill L, Kalivas PW, Wohltmann C (1991) Specificity in the projection patterns of accumbal core and shell in the rat. Neuroscience 41:89-125.

Hjelmstad GO (2004) Dopamine excites nucleus accumbens neurons through the differential modulation of glutamate and GABA release. J Neurosci 24:8621-8628.

Humphries MD, Prescott TJ (2010) The ventral basal ganglia, a selection mechanism at the crossroads of space, strategy, and reward. Prog Neurobiol 90:385-417.

Johnson SW, North RA (1992) Opioids excite dopamine neurons by hyperpolarization of local interneurons. J Neurosci 12:483-488.

Johnson SW, Mercuri NB, North RA (1992) 5-hydroxytryptamine1B receptors block the GABAB synaptic potential in rat dopamine neurons. J Neurosci 12:2000-2006.

Kalivas PW, Churchill L, Klitenick MA (1993) GABA and enkephalin projection from the nucleus accumbens and ventral pallidum to the ventral tegmental area. Neuroscience 57:1047-1060.

Klitenick MA, DeWitte P, Kalivas PW (1992) Regulation of somatodendritic dopamine release in the ventral tegmental area by opioids and GABA: an in vivo microdialysis study. J Neurosci 12:2623-2632.

Koob GF, Volkow ND (2010) Neurocircuitry of addiction. Neuropsychopharmacology 35:217-238.

Laviolette SR, Gallegos RA, Henriksen SJ, van der Kooy D (2004) Opiate state controls bi-directional reward signaling via GABAA receptors in the ventral tegmental area. Nat Neurosci 7:160-169.

Lu XY, Ghasemzadeh MB, Kalivas PW (1998) Expression of D1 receptor, D2 receptor, substance $P$ and enkephalin messenger RNAs in the neurons projecting from the nucleus accumbens. Neuroscience 82:767-780.

Maeda H, Mogenson GJ (1980) An electrophysiological study of inputs to neurons of the ventral tegmental area from the nucleus accumbens and medial preoptic-anterior hypothalamic areas. Brain Res 197:365-377.

Margolis EB, Lock H, Hjelmstad GO, Fields HL (2006a) The ventral tegmental area revisited: is there an electrophysiological marker for dopaminergic neurons? J Physiol 577:907-924.

Margolis EB, Lock H, Chefer VI, Shippenberg TS, Hjelmstad GO, Fields HL (2006b) Kappa opioids selectively control dopaminergic neurons projecting to the prefrontal cortex. Proc Natl Acad Sci U S A 103:2938-2942.

Margolis EB, Fields HL, Hjelmstad GO, Mitchell JM (2008a) $\Delta$-opioid receptor expression in the ventral tegmental area protects against elevated alcohol consumption. J Neurosci 28:12672-12681.

Margolis EB, Mitchell JM, Ishikawa J, Hjelmstad GO, Fields HL (2008b) Midbrain dopamine neurons: projection target determines action potential duration and dopamine $\mathrm{D}_{2}$ receptor inhibition. J Neurosci 28: $8908-8913$

Nader K, van der Kooy D (1997) Deprivation state switches the neurobiological substrates mediating opiate reward in the ventral tegmental area. J Neurosci 17:383-390.

Nair-Roberts RG, Chatelain-Badie SD, Benson E, White-Cooper H, Bolam JP, Ungless MA (2008) Stereological estimates of dopaminergic, GABAergic and glutamatergic neurons in the ventral tegmental area, substantia nigra and retrorubral field in the rat. Neuroscience 152: $1024-1031$.

Nauta WJ, Smith GP, Faull RL, Domesick VB (1978) Efferent connections and nigral afferents of the nucleus accumbens septi in the rat. Neuroscience 3:385-401.

Nugent FS, Penick EC, Kauer JA (2007) Opioids block long-term potentiation of inhibitory synapses. Nature 446:1086-1090.

Olmstead MC, Franklin KB (1996) Differential effects of ventral striatal lesions on the conditioned place preference induced by morphine or amphetamine. Neuroscience 71:701-708.

Olmstead MC, Franklin KB (1997) The development of a conditioned place preference to morphine: effects of lesions of various CNS sites. Behav Neurosci 111:1313-1323.

Omelchenko N, Sesack SR (2009) Ultrastructural analysis of local collaterals of rat ventral tegmental area neurons: GABA phenotype and synapses onto dopamine and GABA cells. Synapse 63:895-906.

Rahman S, McBride WJ (2000) Feedback control of mesolimbic somatodendritic dopamine release in rat brain. J Neurochem 74:684-692.

Scanziani M (2000) GABA spillover activates postsynaptic GABA(B) receptors to control rhythmic hippocampal activity. Neuron 25:673-681.

Sugita S, Johnson SW, North RA (1992) Synaptic inputs to GABAA and GABAB receptors originate from discrete afferent neurons. Neurosci Lett 134:207-211.

Swanson LW (1982) The projections of the ventral tegmental area and adjacent regions: a combined fluorescent retrograde tracer and immunofluorescence study in the rat. Brain Res Bull 9:321-353.

Tripathi A, Prensa L, Cebrián C, Mengual E (2010) Axonal branching patterns of nucleus accumbens neurons in the rat. J Comp Neurol 518:4649-4673.

Usuda I, Tanaka K, Chiba T (1998) Efferent projections of the nucleus accumbens in the rat with special reference to subdivision of the nucleus: biotinylated dextran amine study. Brain Res 797:73-93.

Van Bockstaele EJ, Pickel VM (1995) GABA-containing neurons in the ventral tegmental area project to the nucleus accumbens in rat brain. Brain Res 682:215-221.

White NM, Chai SC, Hamdani S (2005) Learning the morphine conditioned cue preference: cue configuration determines effects of lesions. Pharmacol Biochem Behav 81:786-796.

Xi ZX, Stein EA (1998) Nucleus accumbens dopamine release modulation by mesolimbic GABAA receptors-an in vivo electrochemical study. Brain Res 798:156-165.

Yamaguchi T, Sheen W, Morales M (2007) Glutamatergic neurons are present in the rat ventral tegmental area. Eur J Neurosci 25:106-118.

Yim CY, Mogenson GJ (1980a) Electrophysiological studies of neurons in the ventral tegmental area of Tsai. Brain Res 181:301-313.

Yim CY, Mogenson GJ (1980b) Effect of picrotoxin and nipecotic acid on inhibitory response of dopaminergic neurons in the ventral tegmental area to stimulation of the nucleus accumbens. Brain Res 199:466-473.

Zhang F, Aravanis AM, Adamantidis A, de Lecea L, Deisseroth K (2007) Circuit-breakers: optical technologies for probing neural signals and systems. Nat Rev Neurosci 8:577-581. 